\title{
Primer reporte del Registro Colombiano de Mieloma Múltiple ACHO-Renehoc
}

- Virginia Abello Polo, María Helena Solano, Iván Perdomo, Kenny Galves, José Domingo Saavedra, Álvaro Gómez, Jair Figueroa, Henry Idrobo, Claudia Sossa, Lina María Gaviria

Correo electrónico: virginia.abello@gmail.com

Introducción: la ACHO está comprometida con la creación de un grupo de investigación que se encargue de desarrollar un análisis del patrón epidemiológico de los principales tipos de neoplasias hematológicas en el país. La primera neoplasia que será analizada es el mieloma múltiple (MM); este es el primer reporte preliminar de los hallazgos de este registro, que incluye información de 10 centros con investigadores de la ACHO y cuyo objetivo principal es describir el perfil epidemiológico del MM en la población colombiana y su relación con factores de mal pronóstico.

Métodos: se propone un estudio descriptivo observacional multicéntrico bidireccional (retrospectivo hasta máximo 10 años y prospectivo) de 100 casos de MM en Colombia. Se recolectarán datos sociodemográficos, criterios diagnósticos de las patologías, factores pronósticos e intervenciones terapéuticas. Los datos han sido recopilados usando un Electronic Case Report Form (eCRF), compuesto de pestañas de información de acuerdo con las variables de interés del estudio. Todos los pacientes objeto de reclutamiento y aptos para ser incluidos deberán contar con consentimiento informado firmado antes del ingreso al registro epidemiológico.

Resultados: los datos del registro están en recolección, los resultados estarán disponibles en la fecha final.

Conclusión: los datos del registro están en recolección, los resultados estarán disponibles en la fecha final. 